\title{
Resolution of primary hyperparathyroidism following surgical removal of cervical thymus
}

\author{
Rossella Cannarella ${ }^{1}$, Beniamino Scilletta ${ }^{2}$, Roberto Scilletta ${ }^{2}$, Gaetano Magro ${ }^{3}$, Aldo E. Calogero*1 \\ ${ }^{1}$ Department of Clinical and Experimental Medicine, University of Catania, Catania, Italy \\ ${ }^{2}$ Department of General Surgery, University of Catania, Catania, Italy \\ ${ }^{3}$ Department of Medical and Surgical Sciences and Advanced Technologies, University of Catania, Catania, Italy
}

Received: January 13, 2017

DOI: $10.5430 /$ crim.v4n2p5
Accepted: February 3, $2017 \quad$ Online Published: February 8, 2017

URL: http://dx.doi.org/10.5430/crim.v4n2p5

\begin{abstract}
Recent research has emphasized the capacity of thymus cells of producing parathyroid hormone (PTH) if adequately stimulated, and have investigated the role of the so-called "thymic PTH", produced by the medullary thymic epithelial cells (m-TECs). To the best of our knowledge, only a single case of well-documented PTH secretion from a thymoma causing primary hyperparathyroidism (PHTP) has been reported in the literature so far. We report here the case of a female patient with PHTP who underwent neck exploration for a suspected parathyroid adenoma. After surgery, a normalization of serum PTH concentration was observed, but the histological examination of the surgically excised mass revealed exclusively normal thymus tissue. The present case provides additional evidence of PHTP caused by an ectopic thymus.
\end{abstract}

Key Words: Thymic parathyroid hormone, Primary hyperparathyroidism, Thymus, Parathyroid, Hypercalcemia

\section{INTRODUCTION}

Primary hyperparathyroidism (PHPT) is one of the most common endocrine disorders worldwide. It is biochemically characterized by elevated serum calcium levels and elevated serum parathyroid hormone (PTH) concentrations, ${ }^{[1]}$ whereas PTH serum levels are suppressed in all cases of nonparathyroid hypercalcemia. ${ }^{[2]}$ PHPT is classically associated with nephrolithiasis and nephrocalcinosis in over two-thirds of patients, and with osteitis fibrosa cystica in one-third of cases. ${ }^{[3]}$ Moreover, psychiatric, neurological, cardiovascular and gastrointestinal signs and symptoms can be also present. ${ }^{[4]}$ The most common causes of PHTP include single parathyroid adenoma that accounts for the $85 \%$ of the cases, multiglandular hyperplasia in $10 \%-15 \%$ of cases, and lastly carcinoma in $1 \%$ or less of the cases. In addition uncommon familiar causes do exist, such as MEN-1 and MEN-2A. ${ }^{[5]}$

We report here the case of PHPT apparently due to ectopic secretion of PTH by cervical thymus in a 32-year-old female affected by PHPT. ${ }^{99 \mathrm{~m}} \mathrm{Tc} /{ }^{99 \mathrm{~m}} \mathrm{Tc}-\mathrm{MIBI}$ scintiscan led us hypothesize that it was due to a single parathyroid adenoma. Following its surgical removal, both hypercalcemia and hyper-PTH-emia restored; surprisingly histological examination of the surgically resected specimen revealed exclusively normal thymus. The diagnosis of neuroendocrine tumor was excluded.

\section{Case presentation}

CA is a 32-year old female who initially presented to the Endocrinology Clinic, of the teaching hospital "G. Rodolico", University of Catania, on September 2014 with a history

\footnotetext{
*Correspondence: Aldo E. Calogero, Prof, MD; Email: acaloger@ unict.it; Address: Department of Clinical and Experimental Medicine, University of Catania, Catania, Italy. 
of PHTH. The clinical history of the patient had started 8 months before when she consulted a Nephrology Clinic for recurrent attacks of acute nephrolithiasis. Blood testing revealed PTH levels of $113 \mathrm{pg} / \mathrm{ml}$ (normal range: 15-65) and calcium of $10.4 \mathrm{mg} / \mathrm{dl}$ (normal range: 8.1-10.3). She underwent thyroid-parathyroid ultrasound scan that showed three different hypoechogenic areas adjacent to the thyroid lobes. These nodules with regular margins had normal vascularization. One of them, next to the right lobe, measured $6 \mathrm{~mm} \times 6 \mathrm{~mm} \times 8 \mathrm{~mm}$; the others, located next the left lobe, were of $8 \mathrm{~mm} \times 11 \mathrm{~mm} \times 17 \mathrm{~mm}$ and $5 \mathrm{~mm} \times 7 \mathrm{~mm} \times 8 \mathrm{~mm}$. Thyroid gland volume was slightly higher than normal $(17.6 \mathrm{ml})$ and 4 nodules were described in the left lobe. They measured $3 \mathrm{~mm} \times 3 \mathrm{~mm} \times 5 \mathrm{~mm}$, $3 \mathrm{~mm} \times 3 \mathrm{~mm} \times 4 \mathrm{~mm}, 8 \mathrm{~mm} \times 11 \mathrm{~mm} \times 11 \mathrm{~mm}$ (with perinodular vascularization) and $4 \mathrm{~mm} \times 4 \mathrm{~mm} \times 5 \mathrm{~mm}$ respectively. A subsequent ${ }^{99 \mathrm{~m}} \mathrm{Tc} /{ }^{99 \mathrm{~m}} \mathrm{Tc}-\mathrm{MIBI}$ scintiscan showed an increased uptake in the lower third of the left thyroid lobe. A bone mineral density test revealed a T-score of -0.1 in the lumbar spine and -0.3 in the left hip. Hence the patient was started on Cinacalcet $30 \mathrm{mg} /$ daily and, a couple of weeks later, the dosage was increased to $60 \mathrm{mg} /$ daily. However, she had a low compliance to the treatment because of nausea and vomiting. Consequently, on June 2014, the treatment was stopped and she was referred to the Surgery Unit of the University of Catania Teaching Hospital to be evaluated for parathyroidectomy. A neck magnetic resonance imaging showed a nodule of $13 \mathrm{~mm}$ in the lower third of the left thyroid lobe. At this point she complained acutely of back pain that was referred to nephrolithiasis.

At the end of September 2014, CA underwent surgery. The neck exploration was performed through a transverse cervical incision. Next to the left thyroid lobe, in correspondence to the site of the increased uptake observed with the ${ }^{99 \mathrm{~m}} \mathrm{Tc} /{ }^{99 \mathrm{~m}} \mathrm{Tc}-\mathrm{MIBI}$ scintiscan, there was an oval-shaped, fully capsulated mass, macroscopically similar to a parathyroid adenoma. It was found to be in connection with the thymic corn through a cordon. The nodule was excised, fixed in $10 \%$ buffered formalin and processed by conventional methods.

Haematoxylin and eosin (HE) stain revealed normal thymus with interspersed adipose tissue (see Figure 1). In addition, immunohistochemical analysis (avidin-biotin-peroxidase complex-ABC technique), using a monoclonal rat antihuman PTH antibody (clone 3B3; Dako Diagnostics BV, Glostrup, Denmark) as described elsewhere, ${ }^{[6]}$ was performed to evaluate the presence of PTH. Briefly, after microwave pretreatment and blockage of endogenous peroxidase activity, sections were incubated with the PTH antibody at room temperature. Next, they were incubated with rabbit biotinylated anti-rat IgG and treated with the $\mathrm{ABC}$ standard kit (Vector, Amsterdam, The Netherlands). Peroxidase activity was visualized with $0.5 \% 3.3^{\prime}$-diaminobenzidine tetrahydrochloride (DAB; Sigma-Aldrich Chemie BV, Zwijndrecht, The Netherlands) and $\mathrm{H}_{2} \mathrm{O}_{2} 0.3 \%$ in $0.05 \mathrm{M}$ Tris-HCl. All sections were counterstained with Mayer's haematoxylin for $1 \mathrm{~min}$. Notably immunohistochemical analyses did not reveal any PTH-positive cells. On the contrary, the cells of a histologically normal intra-thyroid parathyroid, obtained from a surgically excised thyroid of another patient with bilateral nodular goiter, were diffusely and strongly stained with PTH antibody, and thus served as external control.

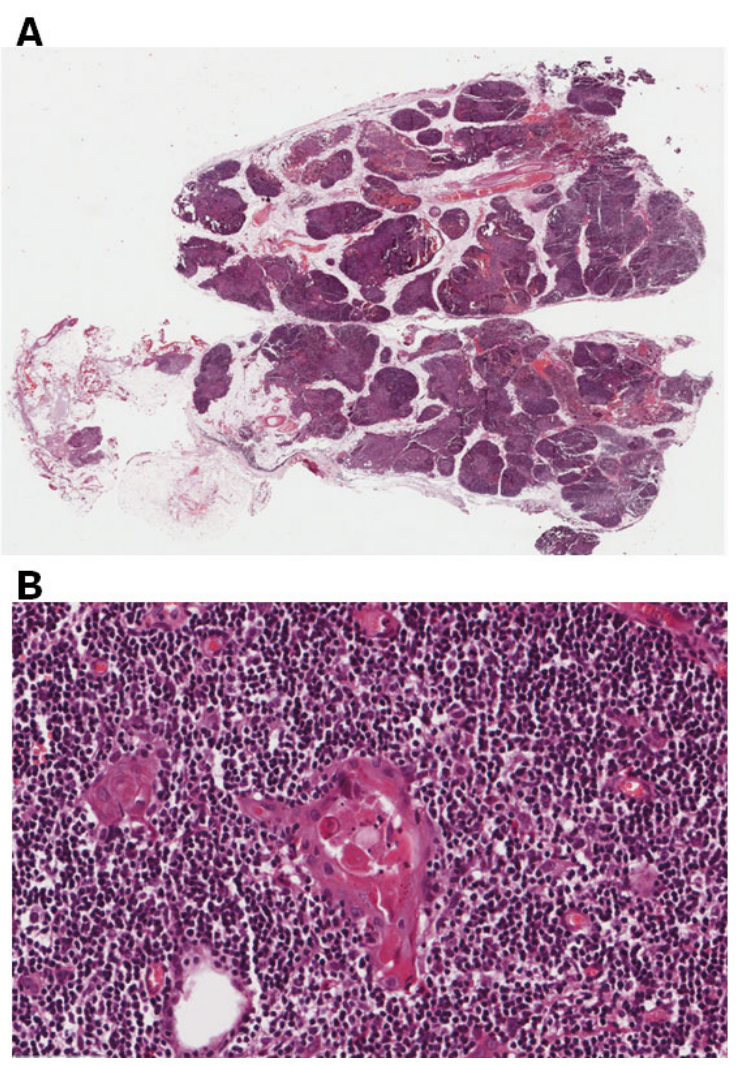

Figure 1. A. Low magnification of the mass surgically removed, showing normal thymus with interspersed adipose tissue (Haematoxylin and eosin staining, $\times 40$ magnification); B. Higher magnification showing lymphocytes and Hassal's corpuscles (Haematoxylin and eosin staining, $\times 250$ magnification).

The patient had an uneventful postoperative course. The follow-up showed a decreasing PTH serum levels at the $2^{\text {nd }}$ postoperative month; then, after an increase at the $3^{\text {rd }}$ month, a definitely reduction until a normalization of serum PTH levels starting from the $3.5^{\text {th }}$ month was observed. In addition, the patient was eucalcemic and no alteration of phosphorous levels was detected during the post-operative follow-up. A 
second ${ }^{99 \mathrm{~m}} \mathrm{Tc} /{ }^{99 \mathrm{~m}} \mathrm{Tc}-\mathrm{MIBI}$ scintiscan performed on January 2015 did not show any increased radionuclide uptake. At the 21th post-operative month, an increase in PTH and calcium serum levels was registered (see Figure 2, panel A), resembling a relapse of hyperparathyroidism. However, the ${ }^{99 \mathrm{~m}} \mathrm{Tc} /{ }^{99 \mathrm{~m}}$ Tc-MIBI scintiscan performed on August $2016 \mathrm{did}$ not show any increased pathologic uptake, and the PTH and calcium serum levels gradually and spontaneously normalized. Such results led us to require chromogranin A and neuron specific enolase (NSE) to exclude the diagnosis of neuroendocrine tumor secreting $\mathrm{PTH}$, but they were within the normal range. The follow-up lasted two years.

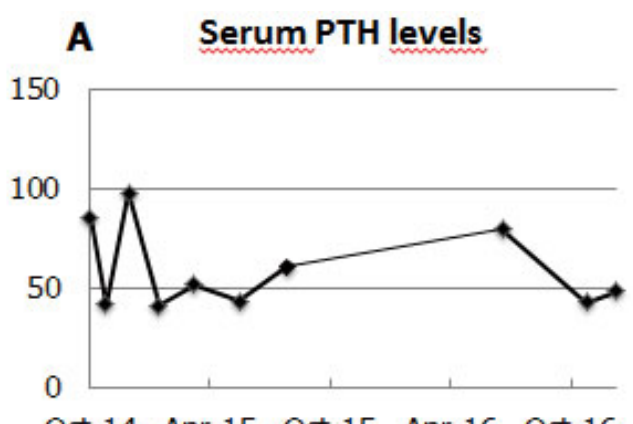

Odt-14 Apr-15 Odt-15 Apr-16 Odt-16
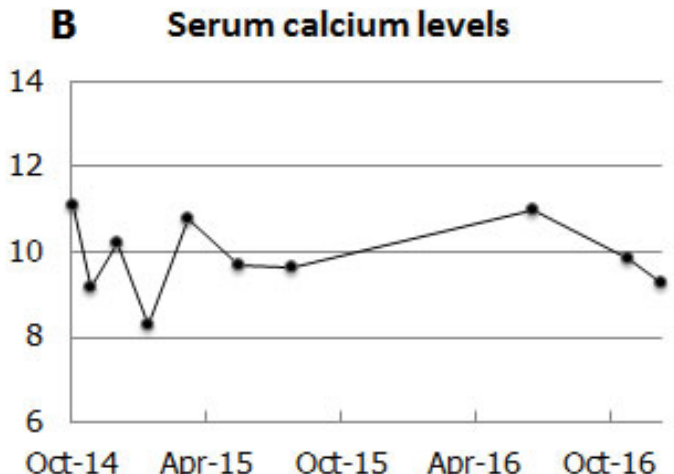

\section{Serum phosphorous levels}

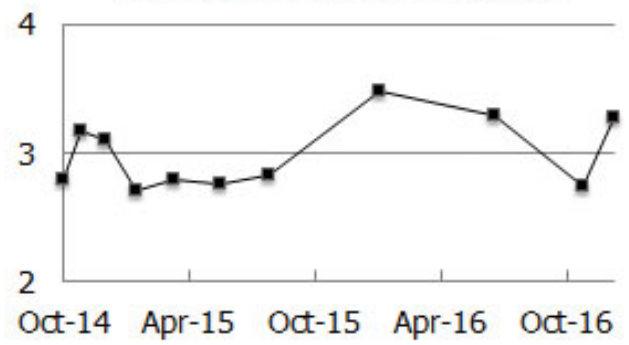

Figure 2. Serum parathyroid hormone (PTH, pg/ml) (A), calcium (mg/dl) (B) and phosphorous (mg/dl) (C) levels after surgery. PTH, calcium and phosphorous normal range are $15-65 \mathrm{pg} / \mathrm{ml}, 8.4-10.2 \mathrm{mg} / \mathrm{dl}, 2.7-4.5 \mathrm{mg} / \mathrm{dl}$, respectively.

\section{Discussion}

Thymus and inferior parathyroid glands share the same embryologic origin (third pharyngeal pouch) and are intimately anatomically connected, whereas the superior parathyroid glands originate from the fourth pharyngeal pouch. Their common embryological origin could explain the reason why the most common ectopic site of parathyroid adenomas is the thymus. ${ }^{[7]}$ Moreover, a few cases of concurrent thymus and parathyroid pathology, such as thymoma and parathyroid adenoma with or without miastenia gravis, are described in the literature. ${ }^{[8-10]}$

We report a case of apparent PTH secretion from thymus tissue. In fact, the normalization of PTH serum levels after surgery, the post-operatory eucalcemic state and the absence of an increased uptake in the second and third post-operatory ${ }^{99 \mathrm{~m}} \mathrm{Tc} /{ }^{99 \mathrm{~m}} \mathrm{Tc}-\mathrm{MIBI}$ scintiscan led us to hypothesize that the mass surgically removed overproduced PTH and was the cause of the PHTP. Although it was macroscopically similar to a parathyroid adenoma, according to histological examination, the whole tissue removed was composed of normal thymic tissue with interspersed adipose tissue. Moreover, the presence of parathyroid cells in the excised tissue was excluded by immunohistochemistry.

A case of PTH secretion from a thymoma has been already documented by Rizzoli and colleagues. They reported a case of PHTP affecting a 25-year-old-male, caused by a superior retrosternal tumefaction surgically removed. Histological examination showed a predominantly epithelial thymoma without any detectable parathyroid glands. Tumor extracts contained immunoreactive PTH material, but PTH-positive cells were absent. Northern blot analysis revealed a PTH messenger ribonucleic acid transcript to a size similar to that found in adenoma or hyperplasia. ${ }^{[11]}$ Moreover, chromogranin A was absent. These results support the ectopic production of authentic PTH (1-34) by a thymoma, indicating a novel tumoral cause of PHTP.

Nevertheless, is thymic tissue capable of produce PTH? Moreover, what is its significance? Recently, the extraparathyroid PTH production in the thymus (the so called "thymic PTH") has been described ${ }^{[11]}$ to explain the higher than expected survival rate for aparathyroid Gcm2-/- mutants mice $(\mathrm{Gcm} 2$ is required for the differentiation and survival of parathyroid precursor cells $\left.{ }^{[12]}\right)$. According to these authors, thymic PTH could represent an auxiliary source of PTH and could extend the survival rate of these mice. They propose that its production may derive from two different mechanisms: 1) the incomplete separation of parathyroid and thymus organs during organogenesis resulting in isolated, misplaced parathyroid cells often attached to the thymus; 
2) the expression of PTH from medullary thymic epithelial cells (mTECs). Human embryos analysis of thymus and parathyroid organogenesis indicate that these mechanisms may be also true for human parathyroid development model. ${ }^{[12]}$ mTECs express different ectodermal, endodermal and neuroectodermal derivates that play an important role in maintaining self-tolerance. ${ }^{[13,14]}$ Therefore, it is believed that m-TECs PTH could act like a self-antigen in the negative selection process. ${ }^{[12]}$ Accordingly with Liu and colleagues, while parathyroid cells localized into the thymus produce PTH in a Gcm2-dependent manner, differentiated mTECs express PTH independently of Gcm2, in a FoxN1-dependent manner. Since thymus-derived PTH ameliorated the lethality phenotype of Gcm2-/- mice, and since it totally derives from m-TECs, ${ }^{[12]}$ it can be concluded that the prolonged survival rate of mutant mice is entirely due to $\mathrm{PTH}$ produced by $\mathrm{m}$ TECs, playing a possible role in serum calcium physiology.

In addition to m-TECs, it seems that also epithelial cells lining thymic cysts do express PTH, as well as calcitonin and thyreoglobulin. ${ }^{[15]}$ Despite morphological and organizational differences, conventional m-TECs and thymic cysts epithelium display considerable phenotypic similarities and a history of FoxN1 expression. Seeing as parathyroid and follicular thyroid epithelial cells differentiation is based on FoxN1 expression too, it can be derived that FoxN1 expression per se is not a definitive marker for thymic lineage differentiation among pharyngeal endoderm derived epithelial tissues, ${ }^{[15]}$ but it represents a common marker for thymus, thyroid and parathyroid development. This thymus and parathyroid common developmental factor could prob- ably explain thymic cells capacity of producing PTH under specific stimuli.

Indeed, a recent study showed that thymus cells could be considered as parathyroid-like precursor cells since, if adequately stimulated, they are capable of secreting PTH. The authors of this research treated human thymus cells utilizing 13 weeks exposure to activin A and soluble sonic hedhehog (Shh). The so obtained differentiated cells expressed PTH, calcium sensing receptor, chemokine receptor type- 4 (CRCR4) and chorian-specific transcription factor (GCM2). Moreover, these cells responded as parathyroid cells to physiologic stimuli, suppressing the PTH secretion in response to increased calcium concentration. ${ }^{[16]}$ On this account, the authors underline the possibility of a therapeutic role of this new parathyroid cells obtained from the thymus tissue to restore parathyroid function in cases of hypoparathyroidism.

In conclusion, thymus tissue that was removed from our patient was included in a capsulated cervical mass, next to thyroid lobe, anatomically connected to thymus through a cord and macroscopically similar to a parathyroid adenoma. This tissue may represent a remnant of pharyngeal endoderm that has not been incorporated during thymic organogenesis and it could not have lost or could have acquired the capacity of producing PTH. At the lights of the evidence previously discussed, probably a novel tumoral cause of PHTP does exist and the role of "thymic PTH" should be examined in depth.

\section{CONFlicts OF INTEREST Disclosure}

The authors have no competing interests to declare.

\section{REFERENCES}

[1] Eastell R, Arnold A, Brandi ML, et al. Diagnosis of asymptomatic primary hyperparathyroidism: Proceedings of the Third International Workshop. J Clin Endocrinol Metab. 2009; 94(2): 340-50. PMid:19193909 https : //doi.org/10.1210/jc. 2008-1758

[2] Bilezikian JP, Mulder JE, Silverberg SJ. Hypercalcemic states: differential diagnosis and acute management. In: Coe FL, Favus MJ, editors. Disorders of Bone and Mineral Metabolism. 2. Philadelphia, PA: Lippincott, Williams \& Wilkins; 2008.

[3] Albright F, Aub JC, Bauer W. Hyperparathyroidism: a common and polymorphic condition as illustrated by seventeen proved cases from one clinic. JAMA. 1934; 102: 1276-87. https://doi.org/10.1 $001 /$ jama. 1934.02750160010003

[4] Silverberg SJ, Walker MD, Bilezikian JP. Asymptomatic Primary Hyperparathyroidism. J Clin Densitom. 2013; 16(1): 14-21. PMid:23374736 https ://doi.org/10.1016/j.jocd.2012.11 .005

[5] Pallan S, Khan A. Primary hyperparathyroidism: Update on presentation, diagnosis, and management in primary care. Can Fam Physician.
2011; 57(2): 184-9. PMid:21321169

[6] Den Hertog E, Goossens MM, van der Linde-Sipman JS, et al. Primary hyperparathyroidism in two cats. Vet Q. 1997; 19(2): 814. PMid:9225438 https://doi .org/10.1080/01652176.1997. 9694746

[7] Jaskowiak N, Norton JA, Alexander HR, et al. A prospective trial evaluating a standard approach to reoperation for missed parathyroid adenoma. Ann Surg. 1996; 224(3): 308-20. PMid:8813259 https://doi .org/10.1097/00000658-199609000-00007

[8] Palin SL, Singh BM. Primary hyperthyroidism due to a parathyroid adenoma with subsequent myasthenia gravis. QJM. 2000; 93(8): 560-1. https://doi.org/10.1093/qjmed/93.8.560

[9] Triggiani V, Guastamacchia E, Lolli I, et al. Association of a wide invasive malignant thymoma with myastenia gravis and primary hyperparathyroidism due to parathyroid adenoma: case report and review of the literature. Immunopharmacol Immunotoxicol. 2006; 28(2): 377-85. https://doi.org/10.1080/08923970600809587

[10] Ceriani L, Giovanella L. Simultaneous imaging of pericardial thymoma and parathyroid adenoma by sestamibi scan. Clin Nucl Med. 
2008; 33(8): 542-4. PMid:18645372 https://doi.org/10.109 7/RLU. Ob013e31817dec15

[11] Rizzoli R, Pache JC, Didierjean L, et al. A thymoma as a cause of true ectopic hyperparathyroidism. J Clin Endocrinol Metab. 1994; 79(3): 912-5. PMid:8077382

[12] Liu Z, Farley A, Chen L, et al. Thymus-associated parathyroid hormone has two cellular origins with distinct endocrine and immunological functions. PloS Genet. 2010; 6(12): e1001251. PMid:21203493 https://doi.org/10.1371/journal.pgen.1001251

[13] Derbinski J, Schulte A, Kyewski B, et al. Promiscuous gene expression in medullary thymic epithelial cells mirrors the peripheral self. Nat Immunol. 2001; 2(11): 1032-9. PMid:11600886 https://doi.org/10.1038/ni723
[14] Derbinski J, Gäbler J, Brors B, et al. Promiscuous gene expression in thymic epithelial cells is regulated at multiple levels. J Exp Med. 2005; 202(1): 33-45. PMid:15983066 https://doi .org/10. 108 $4 / j$ em. 20050471

[15] Dooley J, Erickson M, Farr AG. Lessons from thymic epithelial heterogeneity: FoxN1 and tissue-restricted gene expression by extrathymic, endodermally derived epithelium. J Immunol. 2009; 183(8): 5042-9. PMid:19786540 https://doi .org/10.4049/ji mmunol. 0901371

[16] Woods Ignatoski KM, Bingham EL, Frome LK, et al. Directed transdifferentiation of thymus cells into parathyroid-like cells without genetic manipulation. Tissue Eng Part C Methods. 2011; 17(11): 1051-9. PMid:21797755 https://doi.org/10.1089/ten.tec. 2011.0170 